\title{
BMJ Open Retrospective analysis of alcohol testing in trauma team activation patients at a Canadian tertiary trauma centre
}

\author{
Mete Erdogan, ${ }^{1}$ Nelofar Kureshi, ${ }^{2,3}$ Saleema A Karim, ${ }^{4}$ John M Tallon, ${ }^{5}$ \\ Mark Asbridge, ${ }^{6}$ Robert S Green ${ }^{1,2}$
}

To cite: Erdogan M, Kureshi N, Karim SA, et al. Retrospective analysis of alcohol testing in trauma team activation patients at a Canadian tertiary trauma centre. BMJ Open 2018;8:e024190. doi:10.1136/ bmjopen-2018-024190

- Prepublication history and additional material for this paper are available online. To view these files, please visit the journal online (http://dx.doi. org/10.1136/bmjopen-2018024190).

Received 10 July 2018 Revised 12 0ctober 2018 Accepted 25 October 2018

Check for updates

(C) Author(s) (or their employer(s)) 2018. Re-use permitted under CC BY-NC. No commercial re-use. See rights and permissions. Published by BMJ.

For numbered affiliations see end of article.

Correspondence to Dr Robert S Green; greenrs@dal.ca

\section{ABSTRACT}

Objectives Although alcohol screening is an essential requirement of level I trauma centre accreditation, actual rates of compliance with mandatory alcohol testing in trauma patients are seldom reported. Our objective was to determine the prevalence of blood alcohol concentration (BAC) testing in patients requiring trauma team activation (TTA) for whom blood alcohol testing was mandatory, and to elucidate patient-level, injury-level and system-level factors associated with BAC testing.

Design Retrospective cohort study.

Setting Tertiary trauma centre in Halifax, Canada.

Participants 2306 trauma patients who required activation of the trauma team.

Primary outcome measure The primary outcome was the rate of BAC testing among TTA patients. Trends in BAC testing over time and across patient and injury characteristics were described. Multivariable logistic regression examined patient-level, injury-level and system-level factors associated with testing.

Results Overall, $61 \%$ of TTA patients received BAC testing despite existence of a mandatory testing protocol. Rates of BAC testing rose steadily over the study period from $33 \%$ in 2000 to $85 \%$ in 2010 . Testing varied considerably across patient-level, injury-level and system-level characteristics. Key factors associated with testing were male gender, younger age, lower Injury Severity Score, scene Glasgow Coma Scale score $<9$, direct transport to hospital and presentation between midnight and 09:00 hours, or on the weekend.

Conclusions At this tertiary trauma centre with a policy of empirical alcohol testing for TTA patients, BAC testing rates varied significantly over the 11-year study period and distinct factors were associated with alcohol testing in TTA patients.

\section{INTRODUCTION}

Misuse of alcohol is associated with various problems (physical, social, psychological) and responsible for lost lives, considerable morbidity and significant healthcare costs. ${ }^{1}$ Alcohol use disorder is regularly seen in hospitals and trauma centres, and is associated with traumatic injury (intentional and unintentional) and death. ${ }^{2}$ Emergency department (ED) patients have an over-representation of

\section{Strengths and limitations of this study}

- This observational study was performed at a Canadian tertiary trauma centre with a mandatory clinical policy of testing for alcohol in all patients who require activation of the trauma team.

- We examined how often this mandatory clinical policy of alcohol testing in trauma team activation patients was adhered to over an 11-year study period.

- Our analyses included characteristics of patients, their injuries and the trauma care system to determine the independent association of these factors with alcohol testing.

- Reasons for non-adherence to the mandatory alcohol testing policy and the improvement thereof were not specifically analysed in this study.

- This investigation was limited to the major trauma population at a single centre; thus, our inferences may not be generalisable to other patient populations or institutions.

at-risk drinkers with high weekly consumption or heavy episodic drinking. ${ }^{3}$ Moreover, alcohol-related ED visits predict future problem drinking, alcohol-impaired driving, trauma recidivism and premature death. ${ }^{45}$

Hospitals and trauma centres are often the initial point of contact for patients with alcohol problems, and have a key role in reducing future alcohol-related injuries through brief intervention and/or other treatment programmes as part of trauma care. $^{6} 7$ Routine alcohol screening and brief intervention (SBI) programmes in trauma centres are well established, but not universal. $^{8}$ A survey of ED directors at level I and II trauma centres found only $15 \%$ had formal SBI policies. ${ }^{9}$ Alcohol SBI in EDs or trauma centres is effective at reducing alcohol consumption, ${ }^{10} 11$ impaired driving, ${ }^{12}{ }^{13}$ and injury recidivism. ${ }^{14}$ Blood alcohol concentration (BAC) levels can be readily obtained at presentation or admission when blood is drawn for other diagnostic tests, ${ }^{8}$ or for assessment of alcohol and its effect on the patient's 
presenting condition and injuries (eg, altered level of consciousness, hypotension). ${ }^{15}$

Collectively, evidence supports the development and implementation of policy statements and clinical practice guidelines to promote routine testing of trauma patients for drug and alcohol intoxication. ${ }^{16}$ The American College of Surgeons on Trauma requires level I trauma centres in the USA to test for alcohol disorders. ${ }^{17}$ This was also an expectation of the Trauma Association of Canada, the body responsible for accrediting trauma centres in Canada until 2014. More recently, Accreditation Canada developed criteria for level I trauma centres which included an expectation that alcohol SBI programmes are in place for major trauma patients. ${ }^{18}$

Despite evidence and associated policies, routine testing is not standard practice in most EDs and trauma centres. ${ }^{19}{ }^{20}$ Almost all trauma centres have the capacity to perform BAC measurements and many institutions have adopted a policy of routine testing, yet uniform testing remains elusive. ${ }^{16}$ Lack of proper screening makes it unlikely that patients who misuse alcohol will be identified and receive appropriate interventions and/or treatment. As such, it is important to gain a better understanding of patient-level, injury-level and system-level characteristics associated with routine alcohol testing. Understanding these factors will assist with improving the screening process by identifying gaps-both in terms of patient populations and system-level issues-that are preventing optimal alcohol testing.

The clinical policy (in effect for the entire study period) at the Queen Elizabeth II Health Sciences Centre (QEII HSC), a tertiary trauma centre in Halifax, Nova Scotia, is that the trauma team leader (TTL) is to direct and ensure routine collection of empiric blood alcohol levels for each trauma team activation (TTA) patient (as per protocol and preprinted orders). The purpose of this study was to examine BAC testing in major trauma cases requiring TTA at the QEII HSC over an 11-year period. Our objectives were to determine the prevalence of BAC testing and assess for patient-level, injury-level and systemlevel characteristics associated with blood alcohol testing.

\section{METHODS}

\section{Study setting and population}

This study was conducted at the QEII HSC (Halifax, NS), which is an adult ( $\geq 16$ years) tertiary trauma centre similar to a level I US trauma centre. ${ }^{21}$ Official policy at the QEII HSC is to test all TTA patients for quantitative presence of alcohol. Test results are used for associated clinical management issues, and to initiate intervention and treatment for patients identified to have substance abuse problems. These test results are not used for forensic reasons.

In Nova Scotia, staff of the provincial trauma programme (Trauma Nova Scotia (TNS)) routinely collect detailed information on all major trauma patients; these data are stored in the Nova Scotia Trauma Registry (NSTR). The
NSTR has quality control procedures in place to ensure accurate and complete data entry, and has been used in other peer-reviewed publications. ${ }^{21-25}$ The TNS definition of 'major trauma' includes any injury with an Injury Severity Score (ISS) $\geq 12$ and an appropriate International Classification of Disease External Cause of Injury Code, as well as penetrating injury cases with an ISS $\geq 9$ and any TTAs regardless of ISS. Criteria for TTA include physiological, anatomical, mechanistic and logistic considerations. ${ }^{26}$ All adult TTA cases recorded in the NSTR over an 11-year period (2000-2010) were eligible for this study. There were no changes to the criteria for TTA during this time. This study was performed in accordance with the Strengthening the Reporting of Observational Studies in Epidemiology guidelines for reporting observational studies. ${ }^{27}$

\section{Patients and public involvement}

Patients or public were not involved in this study.

\section{Variables}

Data on all TTAs during the study period were collected from the NSTR. The primary outcome of interest was whether patients had BAC testing performed, which was dichotomised as 'tested' or 'not tested' for blood alcohol. 'Tested' was defined as obtaining a BAC level that was sent to laboratory for analysis at the time of TTA, patient assessment and resuscitation.

Independent variables consisted of patient-level, injury-level and system-level characteristics, along with year variables. Patient-level characteristics included gender, age, health status (co-morbidities), presence of shock (systolic blood pressure $<90 \mathrm{~mm} \mathrm{Hg}$ ), respiratory failure (intubation) and patient outcome (length of stay, discharged alive). Injury-level characteristics included ISS, Glasgow Coma Scale (GCS) score at the scene and on ED arrival, injury type (blunt, penetrating, burn), injury mechanism (falls, motor vehicle crash, assault, other (poisoning, self-harm)), presence of head injury, severe traumatic brain injury (Abbreviated Injury Scale (AIS) Head score $\geq 3$ ) and time from injury to treatment in the ED. System-level characteristics included presence of a surgeon versus non-surgeon as TTL, ${ }^{22}$ transport to ED (transfer vs direct arrival, ie, no intermediate hospital involvement), transport mode (ambulance vs air transport (helicopter and fixed-wing aircraft)), admission to operating room (OR) directly from ED and whether the patient was exposed to any OR procedures. In addition, we captured time of day, day of week and season, and we examined the yearly trend in testing over the study period.

\section{Data and statistical analysis}

Data analysis followed two stages. First, we described characteristics (patient-level, injury-level and system-level) of TTAs, stratified by whether blood alcohol was tested or not. $\mathrm{X}^{2}$ tests for categorical variables and Student's t-tests with $95 \%$ CIs for continuous variables (age, length of stay, 
Table 1 Descriptive statistics for patient-level and injury-level characteristics all trauma team activations in Nova Scotia, 2000-2010, by blood alcohol screening $(n=2306)$

\begin{tabular}{|c|c|c|c|}
\hline Variable & $\begin{array}{l}\text { BAC not tested } \\
\mathrm{n}=891\end{array}$ & $\begin{array}{l}\text { BAC tested } \\
n=1415\end{array}$ & $\begin{array}{l}P \text { values } \\
(95 \% \mathrm{Cl})\end{array}$ \\
\hline Age, mean (SD) & $43.1(19.7)$ & $36.9(16.4)$ & 0.000 (4.70 to 7.70$)$ \\
\hline Gender, male (\%) & $635(71)$ & $1140(81)$ & 0.000 \\
\hline Mechanism of injury, $n(\%)$ & & & 0.000 \\
\hline Falls & 107 (12) & $151(11)$ & \\
\hline MVC & $594(67)$ & $990(70)$ & \\
\hline Assault & $84(9)$ & $183(13)$ & \\
\hline Others* & $106(12)$ & $91(6)$ & \\
\hline Injury type, n (\%) & & & 0.012 \\
\hline Blunt & $772(87)$ & $1212(86)$ & \\
\hline Burn & $15(2)$ & $8(1)$ & \\
\hline Penetrating & $104(12)$ & $195(14)$ & \\
\hline Time from injury†, n (\%) & & & 0.058 \\
\hline$\leq 4$ hours & $404(45)$ & $520(37)$ & \\
\hline$>4$ hours & 275 (31) & $289(20)$ & \\
\hline ISS, mean (SD) & $20.3(14)$ & $19.0(13)$ & 0.023 (0.17 to 2.35$)$ \\
\hline AIS head score $\geq 3, n(\%)$ & $237(27)$ & $456(32)$ & 0.004 \\
\hline Head injury, yes (\%) & $392(44)$ & $677(48)$ & 0.071 \\
\hline GCS-sceneł, n (\%) & & & 0.008 \\
\hline Mild $(<9)$ & $596(67)$ & $871(62)$ & \\
\hline Moderate (9-12) & $76(9)$ & $138(10)$ & \\
\hline Severe $(>13)$ & $129(15)$ & $268(19)$ & \\
\hline GCS-ED arrival§, n (\%) & & & 0.000 \\
\hline Mild (>13) & $570(64)$ & $784(55)$ & \\
\hline Moderate (9-12) & $18(2)$ & $43(3)$ & \\
\hline Severe $(<9)$ & $67(8)$ & $176(12)$ & \\
\hline Shockף, n (\%) & & & 0.109 \\
\hline Shock & $46(5)$ & $55(4)$ & \\
\hline No shock & $797(90)$ & $1321(93)$ & \\
\hline Intubation, yes (\%) & $318(36)$ & $559(40)$ & 0.066 \\
\hline Total comorbidities, mean (SD) & $0.7(1.4)$ & $0.5(1.1)$ & 0.001 (0.08 to 0.28$)$ \\
\hline Length of stay in days, mean (SD) & $18.1(28)$ & $16.5(31)$ & $0.19(-0.81$ to 4.10$)$ \\
\hline Discharged alive & $787(88)$ & $1310(93)$ & 0.001 \\
\hline
\end{tabular}

${ }^{*}$ Others included poisoning and self-harm.

†Data missing for 212 patients in BAC not tested group and 606 patients in BAC tested group.

¥Data missing for 90 patients in BAC not tested group and 138 patients in BAC tested group.

$\S$ Data missing for 236 patients in BAC not tested group and 412 patients in BAC tested group.

IData missing for 48 patients in BAC not tested group and 39 patients in BAC tested group.

AIS, Abbreviated Injury Scale.; BAC, blood alcohol concentration; ED, emergency department; GCS, Glasgow Coma Scale; ISS, Injury Severity Score; MVC, motor vehicle collision.

ISS) were used to note differences between patient populations across all characteristics $(\mathrm{p}<0.05)$. The provincial trauma system in Nova Scotia was accredited in 2005, and we compared testing rates between pre-accreditation (2000-2005) and post-accreditation (2006-2010) periods. Variables with missing values were noted as such.
Second, we conducted multivariable logistic regression to examine patient-level, injury-level and system-level characteristics associated with BAC testing. All variables significant at $\mathrm{p}<0.20$ were initially included in the regression model. The variable 'trauma system accreditation' was derived from the variable 'years' ( $p$ hi coefficient=1.0, 
Table 2 Descriptive statistics for system-level measures for all trauma team activations in Nova Scotia, 2000-2010, by blood alcohol screening $(n=2306)$

\begin{tabular}{|c|c|c|c|}
\hline Variable & $\begin{array}{l}\text { BAC not } \\
\text { tested } \\
\mathrm{n}=891\end{array}$ & $\begin{array}{l}\text { BAC tested } \\
n=1415\end{array}$ & P values \\
\hline Transport & & & 0.000 \\
\hline Direct & $414(47)$ & $802(57)$ & \\
\hline Transfer & $447(54)$ & $613(43)$ & \\
\hline Mode of transport & & & 0.000 \\
\hline Ground & $578(65)$ & $1022(72)$ & \\
\hline Air ${ }^{*}$ & $313(35)$ & $393(28)$ & \\
\hline Any OR & $547(61)$ & $777(55)$ & 0.002 \\
\hline Post-ED admit to OR & $256(29)$ & $349(25)$ & 0.031 \\
\hline Trauma team leader surgeon & $229(26)$ & $428(31)$ & 0.017 \\
\hline Day of the week & & & 0.000 \\
\hline Monday to Wednesday & $354(40)$ & $439(31)$ & \\
\hline Thursday to Friday & $247(28)$ & $355(25)$ & \\
\hline Saturday to Sunday & $290(33)$ & $621(44)$ & \\
\hline Season & & & 0.282 \\
\hline January to March (winter) & $171(19)$ & 235 (17) & \\
\hline April to June (spring) & $226(25)$ & $346(25)$ & \\
\hline July to September (summer) & $263(30)$ & $459(32)$ & \\
\hline October to December (fall) & $231(26)$ & $375(27)$ & \\
\hline Time of day $†$ & & & 0.000 \\
\hline 00:00-04:59 & $109(12)$ & $352(25)$ & \\
\hline 05:00-09:59 & $65(7)$ & $168(12)$ & \\
\hline 10:00-15:59 & $267(30)$ & $276(20)$ & \\
\hline $16: 00-23: 59$ & $449(50)$ & $618(44)$ & \\
\hline Year & & & 0.000 \\
\hline 2000 & $100(11)$ & $51(4)$ & \\
\hline 2001 & $92(10)$ & $45(3)$ & \\
\hline 2002 & 109 (12) & $58(4)$ & \\
\hline 2003 & $106(12)$ & $47(3)$ & \\
\hline 2004 & $111(13)$ & $103(7)$ & \\
\hline 2005 & $109(12)$ & $148(11)$ & \\
\hline 2006 & $100(11)$ & $144(10)$ & \\
\hline 2007 & $63(7)$ & $185(13)$ & \\
\hline 2008 & $40(5)$ & $192(14)$ & \\
\hline 2009 & $25(3)$ & $227(16)$ & \\
\hline 2010 & $36(4)$ & $215(15)$ & \\
\hline Trauma system accreditation & & & 0.000 \\
\hline Preaccreditation (2000-2005) & $627(70)$ & $452(32)$ & \\
\hline Postaccreditation (2006-2010) & $264(30)$ & $963(68)$ & \\
\hline
\end{tabular}

Data are presented as $\mathrm{n}(\%)$ and $\mathrm{p}$ values from $\chi^{2}$ analysis.

${ }^{*}$ Any transport by air, including helicopter and fixed-wing aircraft. †Data were missing for one patient in the BAC not tested group and one patient in the BAC tested group.

BAC, blood alcohol concentration; ED, emergency department; EMS, emergency medical services; OR, operating room.

$\mathrm{p}=0.000)$ and therefore not included in the multivariable analysis. Characteristics were entered into the model as categorical variables with the exception of age and ISS which were entered as continuous variables. Backward stepwise regression was used to select variables that remained in the model; variables were tested for significance using the likelihood ratio test and non-significant $(p \geq 0.05)$ variables were removed. The Hosmer-Lemeshow goodness-of-fit test was used to assess the appropriateness of the logistic models. As a sensitivity analysis, we included missing data as a level in the regression model.

The rank-based non-parametric Kendall tau-b method was applied to detect any trend in BAC testing between 2000 and 2010. The null hypothesis was no trend in BAC testing over time; the alternate hypothesis was an increasing or decreasing trend in testing over the study period. The sign of the coefficient indicates the direction of the relationship, and its absolute value indicates the strength with larger absolute values indicating stronger relationships. All data analysis was performed using SPSS V.23 (IBM) ${ }^{28}$ and Stata V.11.1. ${ }^{29}$

\section{RESULTS}

\section{Patient-level, injury-level and system-level characteristics}

A total of 2306 cases included were included in the analysis. table 1 compares patient-level and injury-level characteristics between TTA cases screened for alcohol and those not tested.

Patients tested for alcohol had lower mean age (36.9 years vs 43.1 years; $\mathrm{p}<0.001$ ) and were more often male $(81 \%$ vs $71 \% ; \mathrm{p}<0.001)$ and discharged alive $(93 \%$ vs $88 \%$; $\mathrm{p}=0.001$ ) compared with those not tested. A larger proportion of cases without alcohol testing involved patients with higher ISS (20.3 vs 19.0; $\mathrm{p}=0.023$ ). We also observed a greater proportion of tested patients had a severe GCS score at the scene or on ED arrival, or a severe head injury (AIS Head $\geq 3$ ).

Regarding system-level characteristics (table 2), BAC testing was more frequent in patients transported directly from the scene to the ED ( $57 \%$ vs $47 \%$; p $<0.001)$, those arriving by emergency medical services (EMS) ground transport $(72 \%$ vs $65 \% ; \mathrm{p}<0.001)$ and when a TTL surgeon was present ( $31 \%$ vs $26 \%$; $\mathrm{p}=0.017$ ). Testing was less frequent in cases arriving by EMS air (28\% vs $35 \%$; $\mathrm{p}<0.001)$ and in patients admitted to OR from the ED (25\% vs $29 \%$; $\mathrm{p}=0.031$ ) or who went to OR at any time for a procedure ( $55 \%$ vs $61 \%$; $\mathrm{p}=0.002$ ). Rates of alcohol testing were significantly higher in the postaccreditation period compared with the preaccreditation period.

Overall, $61 \%$ of the sample received a blood alcohol test, though a clear trend to testing was observed. In 2000, $34 \%$ of TTA patients were tested, a rate that increased to $90 \%$ in 2009 and $86 \%$ in 2010 (figure 1). Still, there remained $10 \%-17 \%$ of TTA patients who were not screened between 2008 and 2010 despite the existence of a mandatory clinical policy to test every TTA patient for alcohol. Time-trend analysis yielded a Kendall tau-b correlation coefficient for BAC testing incidence of 0.36 $(p<0.001)$, indicating a significant increase in testing rates over the course of the study. figure 1 also shows mortality 


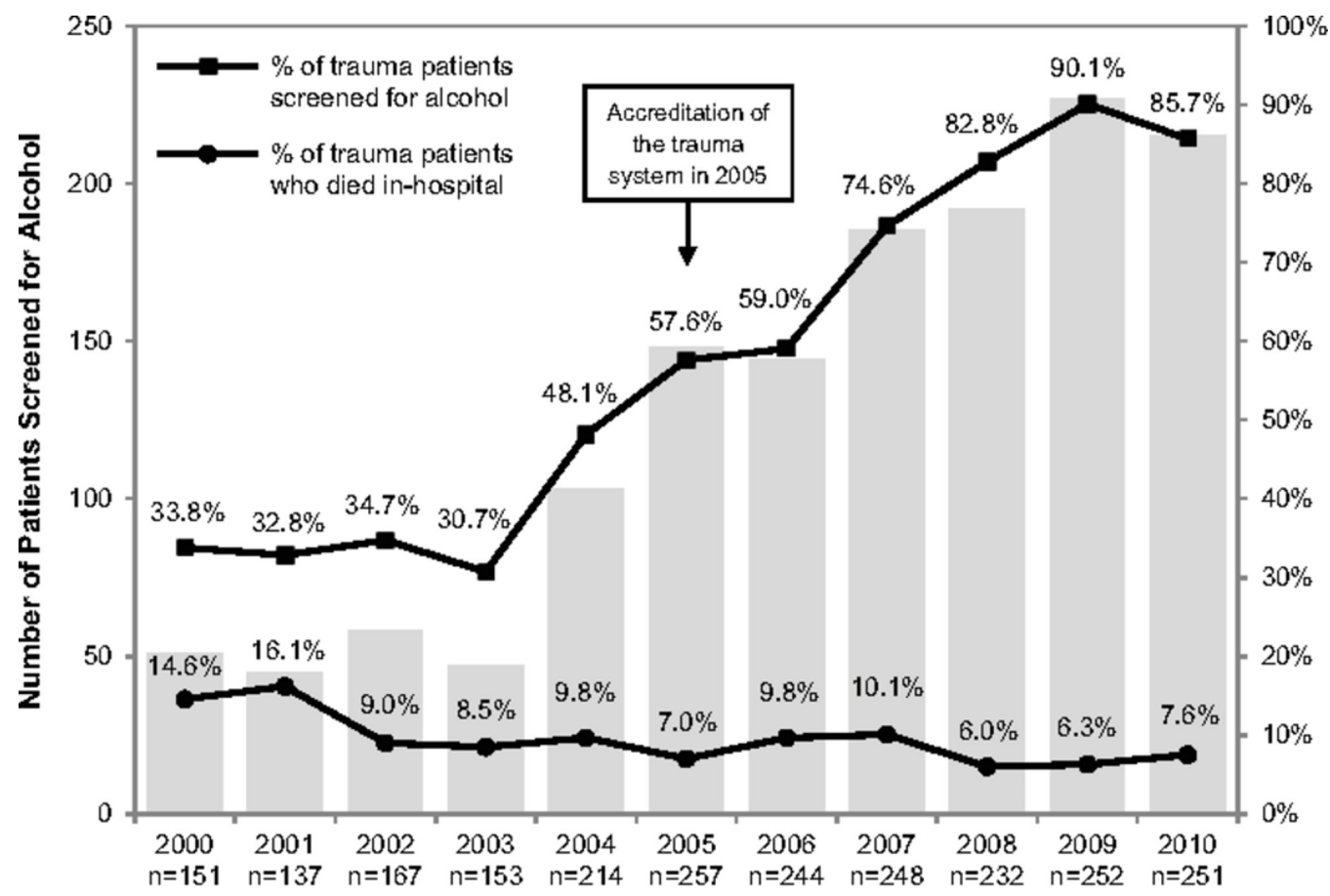

Year \& Total Number of Trauma Team Activations

Figure 1 Blood alcohol testing and mortality in trauma team activation patients, 2000-2010.

for TTA patients during the study. Although there appears to be a trend over time toward lower mortality in these patients, it is likely that other factors in addition to BAC testing contributed to this trend.

\section{Predictors of BAC testing in TTA patients}

The results of multivariable logistic regression are reported in table 3 .

The following variables were included in the final model: age, gender, injury mechanism, ISS, scene GCS, transport, time of day, day of week, year, shock, intubation and discharged alive. Results of the Hosmer-Lemeshow test indicated a good fit for the model $(\mathrm{p}=0.305)$.

Alcohol testing was more likely in patients who were younger (OR $0.99 ; 95 \% \mathrm{CI} 0.98$ to 0.99 ) and male (OR $2.00 ; 95 \%$ CI 1.54 to 2.61$)$. With increasing ISS, the likelihood of testing decreased (OR 0.99; $95 \%$ CI 0.98 to 1.00). The likelihood of BAC testing was greater for patients requiring intubation versus those not intubated (OR 1.63; $95 \%$ CI 1.20 to 2.21). Patients in shock were less likely to be tested compared with patients not in shock (OR 0.46; $95 \% \mathrm{CI} 0.27$ to 0.78$)$. In terms of transportation, BAC testing was more likely in patients transported directed from the scene to the ED (OR 1.63; 95\% CI 1.29 to 2.06). Finally, there were significant temporal effects with higher odds of testing on the weekend compared with the first three weekdays (OR 1.51; 95\% CI 1.17 to 1.96), and during early morning hours compared with the rest of the day. Data on shock and scene GCS were missing for some patients; these were included in a sensitivity analysis (online supplementary table 1). With inclusion of this missing data, ISS and shock were no longer associated with
BAC testing, while being discharged alive and sustaining an 'other' injury mechanism were associated.

\section{DISCUSSION}

The findings of this study demonstrate that not all TTA patients underwent alcohol testing despite the existence of a mandatory clinical policy. Thus, having a requirement for alcohol testing in policy format does not reflect clinical implementation. There were significant differences between patients tested for alcohol and those not tested. Patient-level and system-level factors were most strongly associated with testing, particularly gender, age, direct transport from scene to ED and time of arrival. In spite of the steady and significant increase in frequency of alcohol testing at this tertiary trauma centre over the 11-year study period, we continued to identify untested TTA patients.

This study was a retrospective analysis and thus subject to the known limitations of retrospective data collection. Although data were collected from a prospective population-based registry, information was unknown or incomplete in some cases. This investigation was limited to the major trauma population at a single centre; thus, our inferences may not be generalisable to other patient populations or institutions. Furthermore, the reasons for non-adherence to the mandatory BAC testing policy and the improvement thereof were not specifically analysed in this study. Based on the experience of one study author (RG) who is a TTL at the QEII HSC, the most common reason why a TTA patient might not have their BAC tested would be a personnel issue where a member of the 
Table 3 Multivariable logistic regression of blood alcohol testing on patient-level, injury-level and system-level measures

\begin{tabular}{|c|c|c|c|c|}
\hline Variable & $\begin{array}{l}\text { Adjusted } \\
\text { OR }\end{array}$ & SE & $P$ values & $95 \% \mathrm{Cl}$ \\
\hline Age & 0.99 & 0.003 & 0.000 & 0.98 to 0.99 \\
\hline Male & 2.00 & 0.13 & 0.000 & 1.54 to 2.61 \\
\hline \multicolumn{5}{|l|}{ Injury mechanism* } \\
\hline MVCs & 1.21 & 0.18 & 0.306 & 0.84 to 1.74 \\
\hline Assault & 0.95 & 0.26 & 0.845 & 0.57 to 1.57 \\
\hline Other & 0.64 & 0.26 & 0.084 & 0.39 to 1.06 \\
\hline ISS & 0.99 & 0.005 & 0.040 & 0.98 to 1.00 \\
\hline \multicolumn{5}{|l|}{ GCS-scene† } \\
\hline Moderate (9-12) & 1.27 & 0.20 & 0.232 & 0.86 to 1.90 \\
\hline Severe $(<9)$ & 2.24 & 0.19 & 0.000 & 1.55 to 3.23 \\
\hline Transport - Direct & 1.63 & 0.12 & 0.000 & 1.29 to 2.06 \\
\hline \multicolumn{5}{|l|}{ Time of day§ } \\
\hline 00:00-04:59 & 0.96 & 0.23 & 0.846 & 0.61 to 1.50 \\
\hline $10: 00-15: 59$ & 0.31 & 0.22 & 0.000 & 0.20 to 0.47 \\
\hline $16: 00-23: 59$ & 0.50 & 0.20 & 0.001 & 0.33 to 0.74 \\
\hline \multicolumn{5}{|l|}{ Day of the week } \\
\hline Thursday to Friday & 1.07 & 0.14 & 0.621 & 0.81 to 1.42 \\
\hline Saturday to Sunday & 1.51 & 0.13 & 0.002 & 1.17 to 1.96 \\
\hline \multicolumn{5}{|l|}{ Year $^{\star *}$} \\
\hline 2001 & 1.08 & 0.30 & 0.795 & 0.60 to 1.93 \\
\hline 2002 & 1.23 & 0.28 & 0.447 & 0.72 to 2.13 \\
\hline 2003 & 0.96 & 0.29 & 0.891 & 0.54 to 1.69 \\
\hline 2004 & 2.21 & 0.26 & 0.002 & 1.33 to 3.69 \\
\hline 2005 & 3.59 & 0.25 & 0.000 & 2.18 to 5.93 \\
\hline 2006 & 3.81 & 0.26 & 0.000 & 2.30 to 6.30 \\
\hline 2007 & 12.04 & 0.28 & 0.000 & 6.94 to 20.88 \\
\hline 2008 & 15.39 & 0.29 & 0.000 & 8.66 to 27.36 \\
\hline 2009 & 36.94 & 0.33 & 0.000 & 19.28 to 70.76 \\
\hline 2010 & 29.14 & 0.31 & 0.000 & 15.73 to 53.97 \\
\hline Shock†† & 0.46 & 0.27 & 0.004 & 0.27 to 0.78 \\
\hline Intubation & 1.63 & 0.16 & 0.002 & 1.20 to 2.21 \\
\hline Discharged alive & 1.42 & 0.23 & 0.134 & 0.90 to 2.24 \\
\hline
\end{tabular}

Likelihood ratio $\chi^{2}(28)=1962.357, \mathrm{p}=0.000$; Hosmer-Lemeshow $\chi^{2}(8)=9.454, p=0.305$; Pseudo $R^{2}=0.401$.

${ }^{*}$ Referent $=$ falls.

†Referent=mild

$\ddagger$ Referrent=transfer.

§Referent=05:00-09:59.

१Referent=Monday to Wednesday.

${ }^{*}$ Referrent $=2000$.

††Referent=no shock.

GCS, Glasgow Coma Scale; ISS, Injury Severity Score; MVC, motor vehicle collision.

healthcare team is unfamiliar with the protocol or the need to perform a BAC test. Regular educational initiatives targeting all staff involved in the care and management of the TTA patient may help improve awareness of the mandatory BAC testing policy. It is important to note that there is a balance between mandatory BAC testing and potentially unnecessary blood draws. There may be competing priorities (eg, urgent need to perform resuscitation or an operative procedure), and the cost of unnecessary testing must also be considered. In Canada, there exists a national campaign (Choosing Wisely Canada) that engages healthcare professionals and voices the need to reduce unnecessary tests and treatments in healthcare. ${ }^{30}$

Alcohol screening rates vary due to local differences in populations, clinical policies and institutional procedures. MacLeod and Hungerford performed a systematic review of alcohol-related visits to trauma centres in the USA and found screening rates ranged from $31 \%$ to $99 \% .{ }^{31}$ Others have reported rates of $16.6 \%$ in Taiwan, ${ }^{32} 47 \%$ in the USA, ${ }^{33}$ and $49 \%$ in Australia. ${ }^{34}$ Studies of alcohol screening in TTA patients observed rates of $85 \%$ and $87 \%,{ }^{35} 36$ which are comparable to the rates we observed toward the end of the study period. A recent study of all trauma patients in the Canadian province of Alberta found screening rates rose from $51 \%$ in 2001 to $61 \%$ in 2010 , reaching as high as $69 \%$ in $2008 .{ }^{37}$ Similar to our findings, patients were more likely to be screened if they were younger, male, severely injured or an emergency admission to hospital (compared with a direct admission).

The findings of the present study raise two important issues worth further investigation. First, the patterns observed in blood alcohol testing by patient characteristics raise concerns about potential bias among trauma centre staff. This finding suggests that staff members may be making assumptions as to which patients are more likely to be impaired by alcohol. This is not to say that such assumptions are entirely unjust, as there exists a considerable body of evidence demonstrating that younger males account for the majority of patients found to have positive blood alcohol levels on presentation to the ED. ${ }^{16}{ }^{37-39}$ Surprisingly, injury mechanism was not significant in our study in terms of BAC testing, though more severe injuries were tested more often. Second, and equally important, certain system-level factors increased the likelihood of blood alcohol testing. In particular, direct transport from the scene to the ED appears to matter, with testing rates higher among those who arrived directly rather than being transferred from an intermediate hospital. Similarly, while seasonal effects were not evident, testing occurred more consistently in patients who presented late at night and in the early morning hours, and on weekends compared with other times of the week. Again, this may represent assumptions made by staff members during times when excessive consumption is more likely to lead to problem outcomes and a higher volume of alcohol-impaired patients.

Given the extent of non-testing in our study, potential systematic biases suggest missed opportunities for intervention and treatment. For instance, while testing was more likely late at night and in the early morning, patterns in problematic alcohol consumption (particularly among chronic, high-risk users most in need of 
intervention) do not follow the typical peaks and valleys observed among acute alcohol consumers in the general population. ${ }^{40}$ As such, vigilant testing at all hours and across all patient types represents the best approach for reaching both moderate and high-risk drinkers. Recognition of potential systematic biases is an important step towards improving overall testing rates and provides a focal point for additional continuing education. Systematic biases in testing represent clearly modifiable features of hospital care and secondary prevention. Ongoing efforts are necessary to encourage and educate clinical staff about alcohol testing, with a focus on patients who are systematically missed. Comprehensive alcohol testing in the ED remains important for clinical care as a means to identify patients requiring intervention, consultation and treatment, and as a method for continuing regional and national surveillance of the burden of alcohol. ${ }^{41}$

\section{CONCLUSIONS}

At this tertiary trauma centre with a policy of empiric BAC testing for TTAs, actual testing rates varied significantly over the 11-year study period and specific factors (patientlevel, injury-level and system-level characteristics) were associated with testing in this population. These results should inform clinical testing policies to help improve empiric testing and optimise the reach of appropriate, evidence-based interventions for patients with alcohol-related problems.

\section{Author affiliations}

${ }^{1}$ Trauma Nova Scotia, NS Department of Health and Wellness, Halifax, Nova Scotia, Canada

${ }^{2}$ Departments of Critical Care, Emergency Medicine, and Surgery, Dalhousie University, Halifax, Nova Scotia, Canada

${ }^{3}$ Division of Neurosurgery, Department of Surgery, Dalhousie University, Halifax, Nova Scotia, Canada

${ }^{4}$ Department of Health Policy and Management, University of Arkansas for Medical Sciences, Little Rock, Arkansas, USA

${ }^{5}$ Department of Emergency Medicine, Vancouver General Hospital, University of British Columbia, Vancouver, British Columbia, Canada

${ }^{6}$ Departments of Community Health and Epidemiology and Emergency Medicine, Dalhousie University, Halifax, Nova Scotia, Canada

Contributors MA and JMT conceived the research questions and designed the study. SAK performed data collection. ME, NK, MA and SAK performed analysis and drafted the manuscript. ME, NK, RSG, SAK, JMT and MA contributed to data interpretation, critical review and revisions of the manuscript for important intellectual content. All authors approved the final version of the submitted manuscript and agree to be accountable for all aspects of the work.

Funding The authors have not declared a specific grant for this research from any funding agency in the public, commercial or not-for-profit sectors.

Competing interests None declared.

Patient consent Not required.

Ethics approval Nova Scotia Health Authority Research Ethics Board.

Provenance and peer review Not commissioned; externally peer reviewed.

Data sharing statement No additional data available.

Open access This is an open access article distributed in accordance with the Creative Commons Attribution Non Commercial (CC BY-NC 4.0) license, which permits others to distribute, remix, adapt, build upon this work non-commercially, and license their derivative works on different terms, provided the original work is properly cited, appropriate credit is given, any changes made indicated, and the use is non-commercial. See: http://creativecommons.org/licenses/by-nc/4.0/.

\section{REFERENCES}

1. Charalambous MP. Alcohol and the accident and emergency department: a current review. Alcohol Alcohol 2002;37:307-12.

2. Terrell F, Zatzick DF, Jurkovich GJ, et al. Nationwide survey of alcohol screening and brief intervention practices at US Level I trauma centers. J Am Coll Surg 2008;207:630-8.

3. Nordqvist C, Wilhelm E, Lindqvist K, et al. Can screening and simple written advice reduce excessive alcohol consumption among emergency care patients? Alcohol Alcohol 2005;40:401-8.

4. Nunn J, Erdogan M, Green RS. The prevalence of alcohol-related trauma recidivism: A systematic review. Injury 2016;47:551-8.

5. Purssell R, Brown D, Brubacher JR, et al. Proportion of injured drivers presenting to a tertiary care emergency department who engage in future impaired driving activities. Traffic Inj Prev 2010;11:35-42.

6. Nilsen P, Baird J, Mello MJ, et al. A systematic review of emergency care brief alcohol interventions for injury patients. J Subst Abuse Treat 2008;35:184-201.

7. Schermer CR, Apodaca TR, Albrecht RM, et al. Intoxicated motor vehicle passengers warrant screening and treatment similar to intoxicated drivers. J Trauma 2001;51:1083-6.

8. Danielsson PE, Rivara FP, Gentilello LM, et al. Reasons why trauma surgeons fail to screen for alcohol problems. Arch Surg 1999;134:564-8.

9. Cunningham RM, Harrison SR, McKay MP, et al. National survey of emergency department alcohol screening and intervention practices. Ann Emerg Med 2010;55:556-62.

10. Tanner-Smith EE, Risser MD. A meta-analysis of brief alcohol interventions for adolescents and young adults: variability in effects across alcohol measures. Am J Drug Alcohol Abuse 2016;42:140-51.

11. Biffl WL, Schiffman JD, Harrington DT, et al. Legal prosecution of alcohol-impaired drivers admitted to a level I trauma center in Rhode Island. J Trauma 2004;56:24-9.

12. Landy MS, Davey CJ, Quintero D, et al. A systematic review on the effectiveness of brief interventions for alcohol misuse among adults in emergency departments. J Subst Abuse Treat 2016;61:1-12.

13. Chang G, Astrachan BM. The emergency department surveillance of alcohol intoxication after motor vehicle accidents. JAMA 1988;260:2533-6.

14. Schermer CR, Gentilello LM, Hoyt DB, et al. National survey of trauma surgeons' use of alcohol screening and brief intervention. $J$ Trauma 2003;55:849-56.

15. Hosking J, Ameratunga S, Bullen $\mathrm{C}$, et al. Screening and intervention for alcohol problems among patients admitted following unintentional injury: a missed opportunity? N Z Med J 2007;120:U2417.

16. Rootman DB, Mustard R, Kalia V, et al. Perceptions and realities of testing for alcohol and other drugs in trauma patients. J Trauma 2007;63:1370-3.

17. Rotondo MF, Cribari C, Smith RS. Resources for optimal care of the injured patient 2014. American College of Surgeons. https://www. facs.org/ /media/files/quality\%20programs/trauma/vrcresources. ashx (accessed 3 Sep 2017).

18. Accreditation Canada. Trauma distinction Program. $2017 \mathrm{https} / / /$ accreditation.ca/trauma-distinction (accessed 25 Aug 2017).

19. Gentilello LM. Confronting the obstacles to screening and interventions for alcohol problems in trauma centers. J Trauma 2005;59:S137-S143.

20. Schermer CR, Bloomfield LA, Lu SW, et al. Trauma patient willingness to participate in alcohol screening and intervention. $J$ Trauma 2003;54:701-6.

21. Tallon JM, Fell DB, Ackroyd-Stolarz S, et al. Influence of a new province-wide trauma system on motor vehicle trauma care and mortality. J Trauma 2006;60:548-52.

22. Ahmed JM, Tallon JM, Petrie DA. Trauma management outcomes associated with nonsurgeon versus surgeon trauma team leaders. Ann Emerg Med 2007;50:7-12.

23. Green RS, Butler MB, Kureshi N, et al. A retrospective evaluation of pediatric major trauma related to sport and recreational activities in Nova Scotia. CJEM 2016;18:106-11.

24. Hinkewich C, Green R. The impact of etomidate on mortality in trauma patients. Can J Anaesth 2014;61:650-5.

25. Thibault-Halman G, Tallon JM, Ackroyd-Stolarz S, et al. Major traumatic brain injury: time to tertiary care and the impact of a clinical guideline. J Trauma 2011;70:1134-40. 
26. Nova Scotia Trauma Program. QEII HSC trauma team activation criteria. 2013 http://www.cdha.nshealth.ca/system/files/sites/139/ documents/trauma-team-activation-criteria.pdf (accessed 9 Sep 2017).

27. von Elm E, Altman DG, Egger M, et al. Strengthening the Reporting of Observational Studies in Epidemiology (STROBE) statement: guidelines for reporting observational studies. BMJ 2007;335:806-8.

28. IBM Corp. IBM SPSS Statistics for Windows. 23. Armonk, NY: IBM Corp, 2015.

29. StataCorp. Stata statistical software: Release 11. College Station, TX: StataCorp LP, 2009.

30. Choosing wisely canada. 2018 https://choosingwiselycanada.org (accessed 24 Sep 2018).

31. MacLeod JB, Hungerford DW. Alcohol-related injury visits: do we know the true prevalence in U.S. trauma centres? Injury 2011;42:922-6.

32. Rau CS, Liu HT, Hsu SY, et al. Alcohol-related hospitalisations of trauma patients in Southern Taiwan: a cross-sectional study based on a trauma registry system. BMJ Open 2014;4:e005947.

33. Thomas P, Seale JP, Johnson JA, et al. Impact of a quality improvement intervention to increase brief alcohol and drug interventions on a level i trauma service. Am Surg 2016;82:468-73.
34. Browne AL, Newton M, Gope M, et al. Screening for harmful alcohol use in Australian trauma settings. Injury 2013;44:110-7.

35. Langdorf MI, Rudkin SE, Dellota K, et al. Decision rule and utility of routine urine toxicology screening of trauma patients. Eur J Emerg Med 2002;9:115-21.

36. Dunham CM, Chirichella TJ. Trauma activation patients: evidence for routine alcohol and illicit drug screening. PLoS One 2012;7:e47999.

37. McKee J, Widder SL, Paton-Gay JD, et al. A Ten year review of alcohol use and major trauma in a Canadian province: still a major problem. J Trauma Manag Outcomes 2016;10:2.

38. Black K, Asbridge M, Lea S. An overview of injuries to adolescents and young adults related to substance use: data from Canadian emergency departments. CJEM 2009;11:330-6.

39. McDonald AJ, Wang N, Camargo CA. US emergency department visits for alcohol-related diseases and injuries between 1992 and 2000. Arch Intern Med 2004;164:531-7.

40. Delucchi KL, Kaskutas LA. Following problem drinkers over eleven years: understanding changes in alcohol consumption. J Stud Alcohol Drugs 2010;71:831-6.

41. Kisely S, Asbridge M, Connor J, et al. Using administrative health data for the surveillance of interventions for alcohol-related harm among young people. CMAJ 2012;184:49-53. 